\title{
Teaching Effective Policy Memo Writing and Infographics in a Policy Program
}

\author{
Tavishi Bhasin \\ Associate Professor \\ School of Government and International Affairs \\ Kennesaw State University \\ Charity Butcher \\ Associate Professor \\ School of Government and International Affairs \\ Kennesaw State University
}

\begin{abstract}
Both scholarship on education and practice have recently encouraged the inclusion of writing assignments in the classroom, even in introductory courses. Writing-across-the-curriculum (WAC) programs have been implemented across universities and colleges, promoting structured, writing assignments outside of language-based programs and courses. The collective knowledge on the subject highlights the effectiveness of frequent short assignments as being better for achieving learning goals, in comparison to more traditional, longer term papers often assigned in upper-division and graduate political science courses. This paper explains our efforts to revise the curriculum in two of the courses in our Master's in International Policy Management program at Kennesaw State University. In particular, we chose to focus on two types of policy writing, policy memos and infographics. In this paper, we discuss the background of the program and courses, our choices of assignments, and their design and implementation. Further, we present student assessment of how these assignments contributed to their learning in the courses.
\end{abstract}

Keywords: TLC2020, Teaching Research and Writing, Infographics, Policy Memos, graduate education 


\section{Introduction and Review of the Literature}

Both scholarship on education and practice have recently encouraged the inclusion of writing assignments in the classroom, even in introductory courses. Writing-across-the-curriculum (WAC) programs have been implemented across universities and colleges, promoting structured, writing assignments outside of language-based programs and courses. The collective knowledge on the subject highlights the effectiveness of frequent short assignments as being better for achieving learning goals (McMillan, 2014), in comparison to more traditional, longer term papers often assigned in upper-division and graduate political science courses. While there isn't unanimous support for writing assignments being the only or best way for encouraging active learning (Cavdar and Doe, 2012), there is plenty of evidence pointing to short, frequent writing assignments as one of the ways in which student motivation, engagement and learning may be improved (Loggins, 2009; McMillan, 2014; Anson, 2017). These assignments have also been found to be impactful in metacognition, helping students understand their own successes and failures in the learning process (Lusk, 2016).

Faculty across educational levels have long used assignments like one-minute papers for a variety of purposes, including to gauge how much students were able to absorb from a previous session as well as gaps in knowledge and understanding. These papers have been found to be simple, low-tech and effective in increasing student learning (Chizmar, 1998). While faculty may agree on the impact of writing assignments, time and workload concerns may be obstacles, particularly for those with large introductory courses. Recent innovations include computer software that enables students to conduct peer reviews on colleague's writing assignments may aid in overcoming these obstacles (Ishayama and Watson, 2014).

Within the literature on writing and student learning in Political Science, there has been increasing attention paid to policy-based assignments. While traditional assignments focus on encouraging and testing students on their ability to understand, memorize and apply theoretical approaches, these are usually for the audience of one, the instructor. Policy focused writing may be more effective in engaging students and motivating them as they begin to see their audience as larger, one consisting of key policymakers in their area of interest. This broadened sense of an audience could help with active learning, pushing them to make more nuanced connections between different policy approaches and their consequences (Loggins, 2009), bridging the gap between knowledge and practice (McMillan 2014). This policy audience and its impact is even more important for students in graduate programs.

"The goal of successfully communicating with an audience other than the instructor can have far-reaching effects on students' motivation, reflection, and engagement with the writing task." Anson 2017, page 391.

This paper presents our effort to revise the curriculum in two of the courses in our Master's in International Policy Management program at Kennesaw State University. In particular, we chose to focus on two types of policy writing, policy memos and infographics. The following section discusses the background of the program and courses, our choices of assignments, their design and implementation. 


\section{Background on the Program and Courses}

Both authors teach in the Masters in International Policy Management program at Kennesaw State University. An all online program, it consists of 33 credit hours, taught in an online model for a cohort that moves through the program together. The program takes two years to complete and consists of four core courses including a global experience component held in Geneva each year and a capstone project. Our students come from a diverse range of countries with many of them coming in with work experience in a variety of policy areas within U.S. or international organizations. The program enrolls around 10-15 students each year and the students come from a variety of disciplinary backgrounds and have varying levels of methodological and social-science preparedness.

We teach the two introductory courses, World Politics and Governance and Comparative Policy and Politics, taken by the students in the first semester of the program. These courses set the foundation for the rest of the program. With the program's focus on policy management, each faculty member has worked to incorporate more policy-oriented material and assignments into our syllabi. Yet for the first few years we taught these courses, much of both courses looked like traditional graduate-level introductory courses in international relations and comparative politics. We have both used a variety of traditional writing assignments, such as term papers, in the past in these two classes. Ultimately, we found these types of assignments to be quite ineffective in encouraging students to use their analytical skills or providing the training necessary to successfully navigate the international policy field. In particular, students were not building effective skills in writing for their professional careers. Student feedback also highlighted the need for more emphasis on knowledge of the policy-making process and consequences of varying policy choices. Thus, in reflecting on our courses, we both felt compelled to redesign our courses and assignments to help students acquire skills that would prepare them for a career in policy advocacy and implementation.

The following sections briefly explain our choice of the two types of assignments for the foundational courses we teach in our graduate program in policy management and what we have learned from our experience using these assignments in our courses in fall 2019 and from students surveyed at the end of the course. We conclude with lessons and plans for future versions of these courses.

\section{What We Did and Why We Did It That Way}

The proposed redesign consists of two types of changes, curricular and those made to the assignments. The changes would be followed by an assessment of the changes made, gauging their effectiveness for student knowledge and skills. The curricular changes would focus on using the same country/conflict cases across the two courses in International Relations and Comparative Politics. This would allow students to look at a few cases more in-depth, applying their knowledge of both levels of analysis. The second type of change consists of new assignments focused on building professional skills students may be able to use in a variety of policy-advocacy and implementation related careers. We completed the first phase in Fall 2019 
with the redesigned assignments and plan to complete the redesign, with the inclusion of case studies across the two courses, in Fall 2020.

The primary purpose of redesigning these courses was to make policy and analytical skills more central to the courses, starting with those courses at the beginning of the program and ultimately culminating in the capstone course and projects that students will complete at the end of the program. ${ }^{1}$ In keeping with best practices in graduate education, we focused on changing the requirements for the courses from an end-of-the-semester long essay to two sets of connected assignments, four for each class, spread out through the semester. We believe that by providing complementary skills and assignments in multiple courses, students will better learn these skills and strengthen their graduate education and marketability. The students would receive timely, detailed feedback on the first set of assignments to give them enough time to apply it to the second set in each course. We would then be able to survey students at the end of the course, asking them about the effectiveness of the assignments for building these skills.

We encouraged students to build these skills through two assignments across each course with shared rubrics and instructions so that students get consistent practice and a portfolio of four assignments. These assignments focused on creating infographics which helped students build data visualization skills (Appendices 1 and 2) and policy memos (Appendices 3 and 4) where students examined existing policies and their outcomes, analyzing their strengths and weaknesses and presented alternative policy recommendations.

Policy memos provide a clear structure within which students present background knowledge, compare and contrast policy options available to decision makers and their consequences, and usually conclude with advocating for a particular policy option (Chapnick, 2012). All the benefits highlighted in the literature on policy-focused work improving student motivation and engagement with the advantage of providing students with a broader audience of potential readers apply to the writing of these memos. Memos provide students with a canvas for succinctly applying their analytical skills to a particular policy area.

Infographics ask students to provide original data visualizations, illustrating key trends in their policy area of interest. The ability to create simple data visualizations is an increasingly important professional skill, given the availability and use of evidence-based research and evaluation practices across the corporate and non-profit spheres. From simple bar charts and graphs to complex GIS based maps, most decision and policymakers are already used to consuming information in this manner. Popular news media has already prepared us, widely using data visualization to quickly and effectively communicate complex levels of information to

\footnotetext{
${ }^{1}$ It is important to note here that the redesign is part of a larger project that seeks to make connections across the foundational courses and the capstone course at the end of the program. Those changes are beyond the scope of this paper and will be explored in future research.
} 
both experts as well as lay readers through compelling visuals accompanying longer analyses. Studies across disciplines have found infographics to be a foundational tool in education that helps make a lasting impact on student learning (Serkan, 2016), improving motivation and engagement (Alyyhaya, 2019).

"Effective infographics are based on principles from the fields of psychology, usability, graphic design, and statistics with the aim of reducing barriers (limited time, information overload) to understanding important information. They therefore serve an important role in bridging the gap between producers and consumers of information" (Otten, Cheng and Drenowski, 2015).

We designed these assignments to be sequential. The infographic was designed to be a singlepage, consisting of a minimum of two visual representations (a single graph or chart counts as a single representation). The students were asked to select two-three measures from their policy area, locate relevant data across a few decades (where appropriate and possible), create visual representations that best represent the type of data found and best illustrate the need for policy intervention to create change (Appendices 1 and 2). They could also provide small portions of text to support their figures. Ideally a student would provide a succinct title, two clear, relevant, appropriately labeled data visualizations making a compelling case for intervention in a policy area. We provided examples of relevant trends. For the Comparative Policy and Politics course, students chose two countries of focus through the semester, a democracy and a dictatorship. A good infographic in the course may highlight infant mortality rates as well as life expectancy rates in the country, relative to other countries in the same region or economic category, making a clear case for policy intervention to improve these health indicators. In the World Politics and Governance courses, students needed to choose specific topics related to the course materials.

We designed the infographic to have students complete their research on existing policies used in their chosen country or topic area along with their consequences. The students would need to select key measures and also think through the best visualization for each kind of data. The challenge lay in telling a clear, connected and compelling story in a single page format with minimal text. This assignment was designed to have students complete their background research on the country, related to their particular policy area, in advance of working on the policy memo where they would address policy alternatives and their potential consequences.

For the memo (Appendices 3 and 4), students built on the countries and topics from their infographics. We gave the students instructions that asked them to provide a clear descriptive title, an executive summary of the memo, background on policies used by the decisionmakers in the past and consequences illustrated by measures from the policy area. They were asked to make a clear case for intervention, present a minimum of two policy alternatives, compare and contrast these alternatives for positive and potential negative consequences for a multitude of constituencies affected by their implementation. Finally, they were asked to clearly choose a single policy or combination of policies they endorse, present a plan for implementation, parties involved and a clear timeline for the same. 
This assignment was designed to provide students with the opportunity to identify clear policy alternatives for their chosen case and policy area, understand the process of implementation as well as consequences of each policy alternative. We asked for negative consequences of each policy alternative, highlighting that each policy would have some constituencies that may be positively affected while there may also be negative impact for some. Students had to think through each of these options, selecting the one with the widest public good and minimum public harm, real choices made by decision-makers heading government agencies and nonprofits around the world.

We provided the students with clear rubrics, laying out how each assignment would be graded. We intentionally worked to grade the first set of assignments together, for both courses, so the students would have consistent feedback across the courses. We worked to provide swift and detailed feedback, highlighting areas where the students could improve or had failed to follow instructions. However, our focus was on providing clear examples and consistent, regular feedback on how the student could improve in the second set of assignments. This intentional method of frequent, consistent and detailed feedback was based on the current literature on student learning (Ambrose et al., p. 126) which stresses the importance of these for students to develop effective skills through regular practice. The students had four sets of these assignments, giving them repeated opportunities to develop these skills.

The overall goals for our assignments are listed below:

1. For students to gain knowledge of course content.

2. For students to increase their ability to effectively and succinctly summarize important information from the courses.

3. For students to increase their ability to make compelling policy recommendations.

4. For students to increase their ability to analyze important issues in comparative and international politics

5. For students to increase their ability to apply key theories, approaches, and/or concepts in comparative and international politics.

6. For students to increase their ability to visually represent data (infographic).

We plan to share further details of these initial program changes, including specific assignments and rubrics, as well as our initial findings from the survey we conducted at the end of these two Fall classes. We eagerly solicit feedback from colleagues who teach similar courses in professional programs and hope to continue to improve our initiative in the future.

\section{Student Reactions}

As stated previously, the primary purpose of modifying the assignments in our two courses was to enhance student learning, particularly as related to effectively and succinctly summarizing important information from the courses, making compelling policy recommendations, and analyzing and applying key concepts and theories from the courses. We also hoped that the infographic assignment would increase students' ability visually represent data. To assess whether we were successful in these objectives, we surveyed students at the end of both 
courses. Since there were only nine students in the cohort, the survey can only provide limited evidence of the success of these assignments and this process. Still, all nine students enrolled in both courses completed the survey and their feedback provides some sense of how these assignments impacted their learning.

\section{Infographics}

The student feedback related to infographics was generally positive. Figure 1 presents the general results of the students' perceptions of the impact the infographic assignments on various aspects of their learning. As shown, most students reported that the infographic assignments had some or a great deal of impact on their learning in each of these categories. Students reported the infographic assignment as being most impactful in terms of their ability to effectively and succinctly summarize important information and least impactful on their ability to apply key theories, approaches or concepts. This is in-line with our expectations, as the infographics have little application and are largely meant to encourage students to take a large amount of information and visually represent it in a succinct and effective manner.

\section{Figure 1}

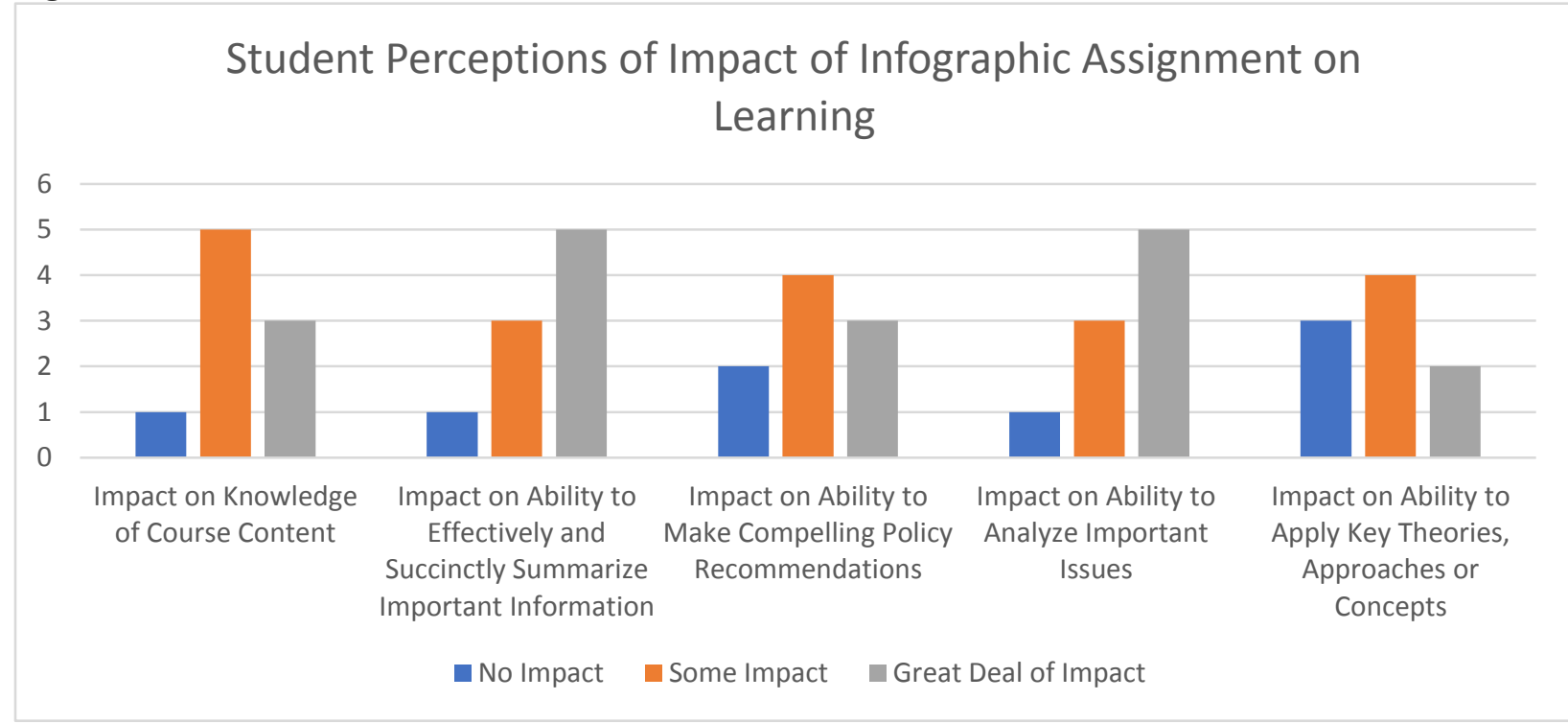

In addition to the above questions, we also asked students if they felt that the infographic assignment impacted their ability to visually represent data in a policy area. Seven out of the 9 students answer yes, with the remaining two saying no. When asked how the infographic impacted this ability, one student replied, "I learned a new skill, which helps me in the future." Another student said that the assignment "taught me how to clearly and concisely relay information." Other students noted the challenging nature of the assignment. As one student noted, "It was a challenge to condense technical and lengthy concepts/data into the infographic format in accordance with the requirements of the assignment, but I was successful for the most part, so I consider this to be a positive impact/improvement from having essentially no experience creating infographics." 
Students were also asked if they felt that the infographic assignment helped them gain skills that they would use in the future (inside and outside of the classroom); six of the students said yes, while three said no. One student mentioned that the infographic assignment helped them in summarizing information. Another student stated that the "infographics taught me to relay information concisely, which will help in essays." Finally, one student felt that the infographic assignment was useful in that it helped them "become a better researcher." Overall, students felt that the infographics were a valuable addition to the courses and believe that these assignments were beneficial to their learning in a variety of ways.

\section{Policy Memos}

Student feedback on the policy memos was very positive. Figure 2 presents the general results of the students' perceptions of the impact the policy memo assignments on various aspects of their learning. In general, few, if any, students felt that these memos had no impact on any category of learning. In fact, the majority of students felt that the policy memos had a great deal of impact on their learning in each category.

\section{Figure 2}

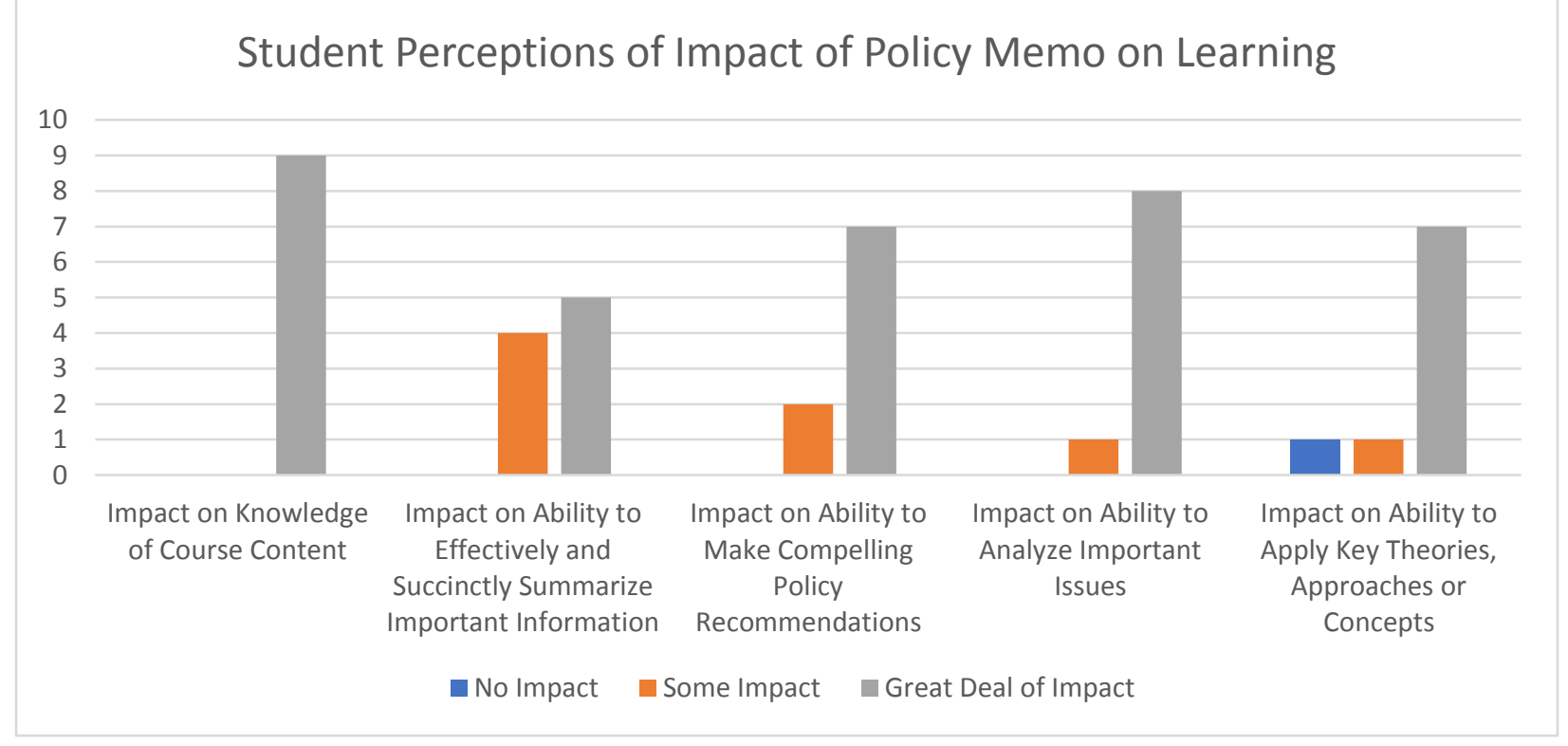

We also asked students if they felt the policy memos impacted their ability to effectively communicate to policymakers; seven students said yes, while two said no. Students were quite positive about the impact of these memos on their learning. One said that the policy memos improved their analytical and critical thinking skills and another mentioned how it enhanced their problem solving skills by giving "a framework on solving problems that could be used outside of politics." Another stated that they "enjoyed the policy memo assignments because they offered the opportunity to research and present information in a format I am interested in mastering." Students also mentioned that policy memos were common "in the real world" and that they were "a good skill to be aware of" and that the assignment "provided a structure for writing proposals: problem, alternatives, solution." 
Students again mentioned the challenging aspects of the assignments, but also that the effort was worthwhile. One student noted that the policy memos "take a lot of work, but they are excellent experiential learning opportunities." Another student noted that the memos helped them to understand the difficulty of implementing policy and that the policy memo assignment was "helpful for anyone entering a policy heavy profession." Overall, the students were quite positive about the benefits of the policy memo assignment and felt that the assignment was beneficial to their learning and future careers.

\section{Reinforcement of Skills}

One of the key elements of this project was that students would be exposed to the same assignments in two concurrent classes, providing the opportunity for practice and improvement. We asked students if they felt that it was helpful to have the same assignments across both courses - eight out of the nine students said yes, with only one saying no. Students provided many reasons why they felt this process was beneficial, but many noted the importance of practice. One student stated, "I believe strongly that an effective method for mastering any type of skill is to perform it, evaluate it, and then continue with the performance and evaluation process." Another said that the mirrored assignments provided consistency, one said, "it was beneficial from the standpoint of repetition and execution. Having multiple opportunities to produce this type of assignment across two courses was helpful." Yet another emphasized that "lots of practice helped make them easier."

Students also appreciated the amount of feedback on their assignments and felt that these comments helped them improve on their work. One student said, "Simply performing the tasks and getting faculty feedback allowed for improvements in the next set of assignments" and another noted they "really appreciated the honest feedback" they received. Overall, students were quite positive about the process of mirrored assignments and felt that the repetition was particularly beneficial, and that detailed faculty feedback helped them improve on their assignments.

\section{Challenges and Areas for Improvement}

Students did note some challenges with having mirrored assignments in each class, and we noticed some of these challenges ourselves. One issue was students getting a bit confused between these assignments for each of the classes. While the assignments were generally the same, there was some minor differences, particularly since one class was a comparative politics course and one was an international relations course. This created some confusing for students - and student sometimes ended up doing assignments incorrected in one of the classes because of this confusion. Relatedly, students might end up making the same mistake twice (once for each class). While we attempted to grade the assignments and provide feedback quickly to avoid this problem, one student, at least, mentioned they felt this was a challenge. One student mentioned that their "biggest challenge was staying motivated" because "the consistence of the assignment sometimes made it not as interesting as it was at the beginning of the semester." 
Based on student feedback and our own observations, there are a few places we believe these assignments can be improved for the future. First, students noted that it would be useful to have some examples of both infographics and policy memos before attempting their own. We plan to provide such examples in the future. Second, we plan to have policy memos be 2-3 pages long for each assignment. We believe this will streamline the assignment, encourage students to be more concise in their language, and force students to choose the most important information for their memo. Third, we plan to reduce the amount of additional assignments in the courses, allow students more time to focus on the infographics and policy memos. Fourth, we plan to provide some additional background to students distinguishing comparative politics from international relations, which we hope will alleviate some of the confusion students had. Finally, some students found this process repetitive, and thus a bit boring. We plan to provide a wider range of assignment topics, as well as have students address their infographics and memos to a variety of audiences, to help reduce repetitiveness and increase interest of students. 


\section{Bibliography}

Anson, Ian G., 2017. "Audience, Purpose, and Civic Engagement: A Reassessment of Writing Instruction in Political Science." Journal of Political Science Education 13 (4): 389-403.

doi:10.1080/15512169.2017.1340166.

Blings, Steffen, and Sarah Maxey. 2017. "Teaching Students to Engage with Evidence: An Evaluation of Structured Writing and Classroom Discussion Strategies." Journal of Political Science Education 13 (1): 15-32. doi:10.1080/15512169.2016.1168303

Cavdar, Gamze, and Sue Doe. 2012. "Learning through Writing: Teaching Critical Thinking Skills in Writing Assignments." PS: Political Science and Politics 45 (2): 298-306.

Chapnick, Adam. 2012. "The Action Memorandum: An Assignment with a Promising Future." Transformative Dialogues: Teaching \& Learning Journal 5 (3): 1-12.

Chizmar, John F., and Anthony L. Ostrosky. 1998. "The One-Minute Paper: Some Empirical Findings." Journal of Economic Education 29 (1): 3-10. doi:http://www-tandfonlinecom.proxy.kennesaw.edu/loi/vece20.

Ishiyama, John, and WendyL. Watson. 2014. "Using Computer-Based Writing Software to Facilitate Writing Assignments in Large Political Science Classes." Journal of Political Science Education 10 (1): 93101. doi:10.1080/15512169.2013.859085

Loggins, Julie A. 2009. "Simulating the Foreign Policy Decision-Making Process in the Undergraduate Classroom." PS: Political Science and Politics 42 (2): 401.

Lusk, Adam. 2016. "Metacognitive Strategies in the Introduction to Political Science Classroom." Journal of Political Science Education 12 (2): 141-50. doi:10.1080/15512169.2015.1060888.

McMillan, Samuel Lucas. 2014. "Bravo for Brevity: Using Short Paper Assignments in International Relations Classes." International Studies Perspectives 15 (1): 109-20. doi:10.1111/insp.12003.

Williams, JulieAnn Stuart, and Randall C. Reid. 2010. "Developing Problem Solving and Communication Skills Through Memo Assignments in a Management Science Course." Journal of Education for Business 85 (6): 323-29. doi:10.1080/08832320903449493. 


\section{Appendices}

IPM 7720: World Politics and Governance is a graduate-level introductory course in international relations.

IPM 7725: Comparative Politics and Policy is a graduate-level introductory course in comparative politics.

Each course utilized the same basic instructions for the infographic and policy memo assignments, with some minor differences related to the course content. The initial assignments for each course are presented below.

\section{Appendix 1}

\section{Infographic Assignment - IPM 7720: World Politics and Governance}

Your task here is to create an infographic (a visual representation) that summarizes the topic you have chosen related to challenges to the state.

The focus here is on looking back at how this topic/policy area has been handled the past. Summarize the challenges faced this policy area. Tell a clear story with the goal of convincing the reader that it is imperative that changes be made in this policy area.

\section{Each infographic should include a minimum of two charts/graphs/maps/other visual} representation of data. Multiple trends may be highlighted within each chart.

2. Please ensure you create the visual representations yourself and do not copy someone else's work.

3. To create your infographic, you should choose two or three indicators (measures) that are relevant to your policy area. For example, number of deaths from international terrorist attacks might be one measure of the problem faced by terrorism. Statistics on the global arms trade, or global human trafficking might be other examples. Using a reliable data source, clearly find and state the current statistics for those measures. Summarize the trends over the last few decades on these measures. Remember, this is a class on international relations, so your measures should apply broadly to challenges faced by states and should not be specific to a single country (unlike your infographic in IPM 7725).

4. We expect you will use data from existing data sources, such as the World Bank. Enter the data into Word/Excel/other data analysis software. Then use this data that you have entered into Excel to create a chart/graph/other visual representation. You may copy the chart or graph into word when you are done.

5. Each infographic should have a title that clearly summarizes the overall purpose of the infographic. Subsections and charts/representations should have relevant titles as well.

6. Your infographic should be designed to tell a coherent story using the visual representations and text within it.

7. Your infographic may include short portions of text in addition to the charts/visual representations that it contains.

\section{Rubric}

100 points 
1. Titles - Main and sub-sections.

Clear, relevant, summarizes concepts. 5

2. Contains at least two charts/visual representations covering at least two separate trends relevant to the policy area. 10

3. Effectiveness

a. Infographic presents a coherent overall story summarizing questions. 10

b. Each data representation is clearly connected to the central theme of the infographic. 10

c. Each data representation provides compelling evidence to support the overall argument of the infographic. 10

d. Contains clear takeaways from the data and information presented. 10

4. Data and information used is from a reliable source 10

5. Data are manipulated and transformed to create an accurate visual representation. 10

6. Data are manipulated and transformed to create a visual representation appropriate for the data and information presented. 10

7. Visual representations are clearly labeled with a legend/key included. 5

8. Writing Style and Grammar. 10 


\section{Appendix 2}

Infographic Assignment - IPM 7725

Your task here is to create an infographic (a visual representation) that summarizes the policy problem or challenge that you are addressing in your chosen country.

1. The focus here is on looking back at how your country has handled this policy area up to this point. Summarize the challenges faced by the faces in this policy area? How has your country addressed these challenges in the past? Tell a clear story with the goal of convincing the reader that it is imperative that changes be made in this policy area.

2. Each infographic should include a minimum of two charts/graphs/maps/other visual representation of data. Multiple trends may be highlighted within each chart.

3. Please ensure you create the visual representations yourself and do not copy someone else's work.

4. To create your infographic, you should choose two or three indicators (measures) that are relevant to your policy area. For example, literacy rates might be one measure used in the area of education. Percentage of population with high school degrees might be another. Using a reliable data source such as the World Bank, clearly find and state the current statistics for those measures. Summarize the trends over the last few decades for your country on these measures. [[Provide some context -- how does your country compare with other countries in its region on these measures?]]

5. Note that at least one of the charts/figures should set up the problem that you will discuss in your policy memo. Think of this as an area for growth/improvement that you will address for which you will have policy recommendations when you write your memo. You are only setting up the problem here, highlighting an area for growth. You don't need to have policy recommendations at this stage.

6. We expect you will use data from existing data sources, such as the World Bank. Enter the data into Word/Excel/other data analysis software. Examples of data could be literacy rates over a few decades for the country. Then use this data that you have entered into Excel to create a chart/graph/other visual representation. You may copy the chart or graph into word when you are done.

7. Each infographic should have a title that clearly summarizes the overall purpose of the infographic. Subsections and charts/representations should have relevant titles as well.

8. Your infographic should be designed to tell a coherent story using the visual representations and text within it.

9. Your infographic may include short portions of text in addition to the charts/visual representations that it contains.

\section{Rubric}

100 points

1. Titles - Main and sub-sections

Clear, relevant, summarizes concepts 5

2. Contains at least two charts/visual representations covering at least two separate trends relevant to the policy area. 10 
3. Effectiveness

a. Infographic presents a coherent overall story summarizing questions 10

b. Each data representation is clearly connected to the central theme of the infographic. 10

c. Each data representation provides compelling evidence to support the overall argument of the infographic. 10

d. Contains clear takeaways from the data and information presented. 10

4. Data and information used is from a reliable source 10

5. Data are manipulated and transformed to create an accurate visual representation. 10

6. Data are manipulated and transformed to create a visual representation appropriate for the data and information presented. The information being presented should be clearly relayed to the reader. 10

7. Visual representations are clearly and appropriately labeled with a legend/key included where necessary. This includes units of analysis for charts and an accurate and descriptive title for each representation. 5

8. Writing Style and Grammar. 10 


\section{Appendix 3}

Policy Memo Assignment - IPM 7720: World Politics and Governance

\section{Policy Memo/Brief Instructions}

The purpose of this assignment is to provide students with the opportunity to practice writing policy memos/briefs, which will be a useful skill in their international policy management career.

\section{What is a policy memo/brief?}

A policy memo/brief is a short document that outlines an issue or problem and presents recommendations based on evidence for a non-specialized audience, such as key decision-makers, NGOs, journalists, etc. It provides policy advice and is meant to be informative and persuasive.

\section{Organization of your policy memo/brief}

While in your professional careers policy memos might vary in their organization, below is a common organizational flow for policy briefs, and one that you must use in these two courses.

- Title: Your title should clearly communicate your topic and may include the position of the writer on the issue. A good title should grab the attention of the reader. (5 points)

- Introductory Paragraph/Executive Summary: Your memo/brief should include a short introductory paragraph that summarizes the problem you are addressing in the memo. In addition, the summary should briefly and clearly state the primary findings and recommendations of the memo. (10 points)

- Description of the Problem and Reasons for Action: You will provide a brief overview of the policy that needs to be addressed and why it is important to do something different than current policy. Basically - what is the problem and why do we need to fix it? In this section, students should discuss key measures that illustrate the problem and failures of current or past policies. For example, current literacy levels and trends might be used to demonstrate the lack of effective current policies. Data and information are important here. You should specifically analyze the strengths and weakness of existing policy - be sure to include both! Do not just present your data, but rather discuss the implications or significant findings based on the data. (20 points)

- Proposed Policy Alternatives: What are some potential alternatives to the current policy based on your research? Specifically, you should discuss the process through which each proposed alternative policy might fix the problems with the current policy. You should include a minimum of two potential policy alternatives. (10 points)

- Analyzing Policy Alternatives and Making a Policy Recommendation: In this section, you will evaluate and analyze the proposed policy alternatives you discussed in the previous section and ultimately make a recommendation on the best course of action. You should discuss the strengths and weaknesses of each policy alternative and clearly state the criteria are you using to evaluate these options. Weigh the costs and benefits of various options (based on these criteria), building an argument for the "best" recommendation. You should support your assertions with relevant data and avoid generalizations. You should also be sure to address potential counterarguments and rebuttals to your findings and ultimate recommendation. The 
key object of this section is to ultimately create a compelling argument for the option that you have chosen as a recommendation from the presented alternatives. (25 points)

- Implementing Policy Recommendation: Clearly state how your policy recommendations should be implemented and a timeframe for implementation. Be sure to provide specific and detailed steps that need to be followed for the implementation of this policy; this requires you to consider the key actors (agencies, leaders, executives, etc.) involved in the implementation. Further, you should discuss the potential (intended or unintended) impact, both positive and negative, of these recommendations on key constituents. (20 points)

- Conclusion: Provide a succinct and clear conclusion. Remind the reader of the "big picture" and overall goal of your policy recommendations - answering the "so what?" question. In other words, why is your proposed alternative better than the current policy and status quo? Why is it important to make this change and why is the proposed timeframe appropriate and necessary? (10 points)

\section{Format of your policy memo/brief}

While the length of policy memos/briefs may vary, since you are still acquiring the ability to write succinctly, for the purpose of these classes your policy memos should be 4-5 pages in length (single spaced). In addition, policy memos should be written with the reader in mind. They should be easy to read and it should be easy to find important information. You may consider bold or italicized fonts, clearly defined subsections, and/or bullets and lists to help the reader quickly and easily find key information.

\section{Additional Grading Information}

This is a formal writing assignment and you are expected to write clearly and for a professional audience. such, clarity and organization of writing, use of appropriate grammar, spelling, and appropriate word choice and usage will be considered when grading your memos. Memos with such mistakes may be penalized up to 10 points, depending on the severity of the problems. 


\section{Appendix 4}

Policy Memo Assignment - IPM 7725

\section{Policy Memo/Brief Instructions}

The purpose of this assignment is to provide students with the opportunity to practice writing policy memos/briefs, which will be a useful skill in their international policy management career.

\section{What is a policy memo/brief?}

A policy memo/brief is a short document that outlines an issue or problem and presents recommendations based on evidence for a non-specialized audience, such as key decision-makers, NGOs, journalists, etc. It provides policy advice and is meant to be informative and persuasive.

\section{Organization of your policy memo/brief}

While in your professional careers policy memos might vary in their organization, below is a common organizational flow for policy briefs, and one that you must use in these two courses.

- Title: Your title should clearly communicate your topic and may include the position of the writer on the policy issue. A good title should also grab the attention of the reader. (5 points)

- Introductory Paragraph/Executive Summary: Your memo/brief should include a short introductory paragraph that summarizes the main problem/gap you are addressing in the memo. In addition, the summary should briefly and clearly state the primary findings and policy recommendations of the memo. (10 points)

- Description of the Problem and Reasons for Action: You will provide a brief overview of the policy that needs to be addressed and why it is important to do something different than current policy. Basically - what is the problem and why do we need to fix it? In this section, students should discuss key measures that illustrate the problem and failures of current or past policies. For example, current inequality or literacy levels and trends might be used to demonstrate the lack of effectiveness of current policies. Data and information are important here. You should specifically analyze the strengths and weakness of existing policy - be sure to include both! Do not just present your data, but rather discuss the implications or significant findings based on the data. (20 points)

- Proposed Policy Alternatives: What are some potential alternatives to the current policy based on your research? Specifically, you should discuss the process through which each proposed alternative policy might fix the problems with the current policy. You should include a minimum of two potential policy alternatives. (10 points)

- Analyzing Policy Alternatives and Making a Policy Recommendation: In this section, you will evaluate the proposed policy alternatives you discussed in the previous section and ultimately make a recommendation on the best course of action. You should discuss the strengths and weaknesses of each policy alternative and clearly state the criteria are you using to evaluate these options. Weigh the costs and benefits of various options (based on these criteria), building an argument for the "best" recommendation. You should support your assertions with relevant data and avoid generalizations. You should also be sure to address potential counterarguments and rebuttals to your findings and ultimate recommendation. The key object of this section is to 
ultimately create a compelling argument for the option that you have chosen as a recommendation from the presented alternatives. ( 25 points)

- Implementing Policy Recommendation: Clearly state how your policy recommendations should be implemented and a timeframe for implementation. Be sure to provide specific and detailed steps that need to be followed for the implementation of this policy; this requires you to consider the key actors (agencies, leaders, executives, etc.) involved in the implementation. Further, you should discuss the potential (intended or unintended) impact, both positive and negative, of these recommendations on key constituents. (20 points)

- Conclusion: Provide a succinct and clear conclusion. Remind the reader of the "big picture" and overall goal of your policy recommendations - answering the "so what?" question. In other words, why is your proposed alternative better than the current policy and status quo? Why is it important to make this change and why is the proposed timeframe appropriate and necessary? (10 points)

\section{Format of your policy memo/brief}

While the length of policy memos/briefs may vary, since you are still acquiring the ability to write succinctly, for the purpose of these classes your policy memos should be 4-5 pages in length (single spaced). Bibliographies do not count towards this page limit. In addition, policy memos should be written with the reader in mind. They should be easy to read and it should be easy to find important information. You may consider bold or italicized fonts, clearly defined subsections, and/or bullets and lists to help the reader quickly and easily find key information.

\section{Additional Grading Information}

This is a formal writing assignment and you are expected to write clearly and for a professional audience. Clarity and organization of writing, use of appropriate grammar, spelling, and appropriate word choice and usage will be considered when grading your memos. Memos with such mistakes may be penalized up to 10 points, depending on the severity of the problems. 
Appendix 5

\section{Venezuela:}

A Medical Crisis and Humanitarian Failure

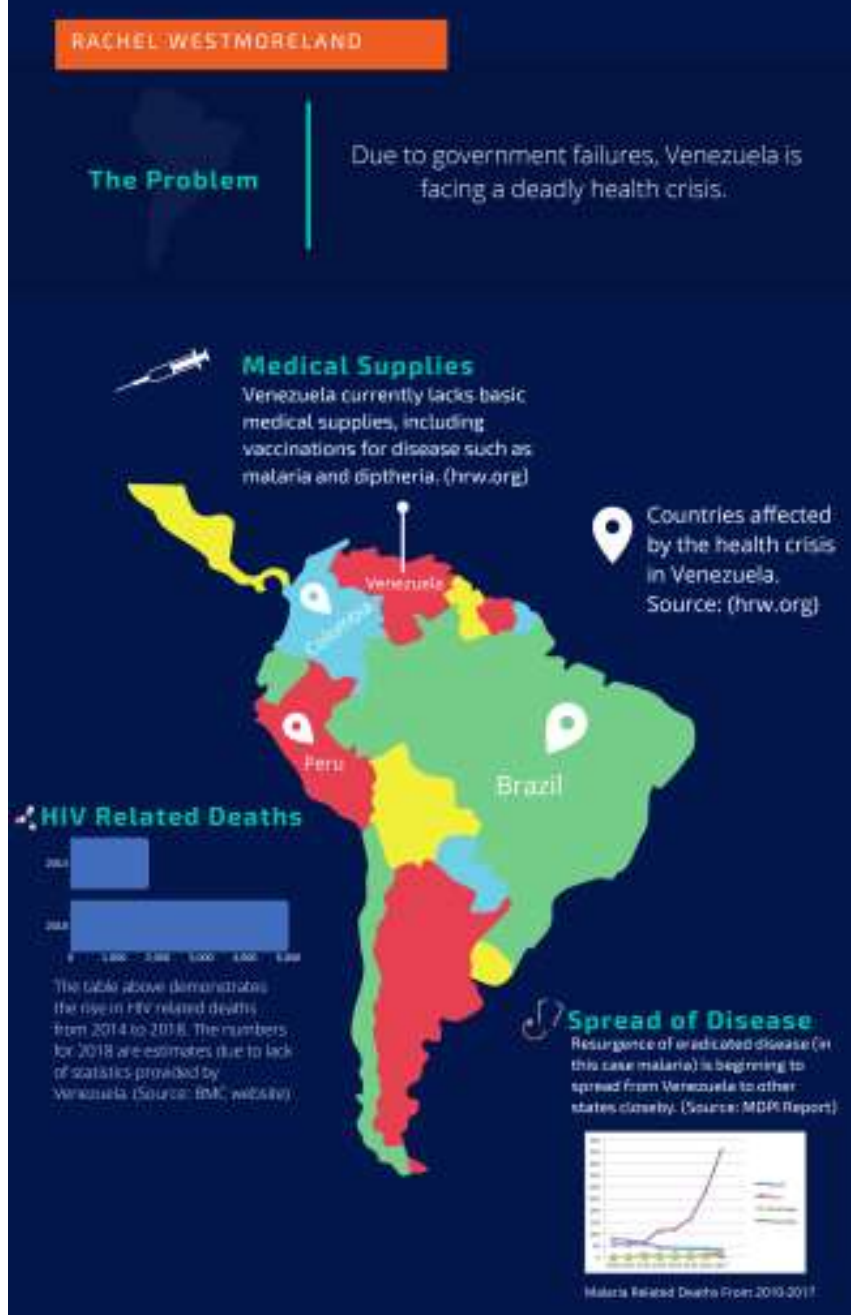

Maternal mortatity rose by

$55 \%$

between 2015 to 2016

(Source-hrworg)
Infant mortatity has nisen by

\section{$30 \%$}

in the same time period

(Sources hrworg] 


\section{Appendix 6 \\ Student Final Policy Memo - IPM 7720}

\section{Introduction}

\section{Climate Change IS Real}

Climate change affects the level of the earth's seas and is causing more fierce storms and weather events worldwide. Rising sea levels are changing coastlines and are threatening entire islands. Tropical storms and hurricanes are stronger and last longer, excessive moisture in the air increases snowfall and rainfall which in turn increases flooding, and drought leaves areas of land unavailable for crops and increases the likelihood of forest fires (The Ocean Portal Team 2018; Stormfax Weather Almanac 2018; Union of Concerned Scientists 2011). People's lives and livelihoods are being affected.

The policy recommendation is to create a worldwide cooperative agreement to reduce greenhouse emissions. The consequences of signing, or not signing, will affect trade with other states either positively or negatively.

\section{Description of the Problem and Reasons for Action}

Climate change affects every part of this earth. One of the consequences of a warmer atmosphere is the increase in sea levels. "As ocean waters warm, they expand," and as polar caps and glaciers melt, the water runoff enters the oceans (GlobalChange.gov, n.d.). Although the increase in sea levels seems slow, it has increased faster in the last five years than at any time since 1993 (World Meteorological Organization 2019). Since 1992, sea levels have risen from 3-9 inches depending on topography (Garner and Dunbar 2017). If the seas continue to rise at this rate, coastlines will change, and even entire islands will disappear beneath the water. Some low-lying islands are already being affected: islands are shrinking, seawater has destroyed clean drinking water, flooding is increasing, and storms are stronger (The Ocean Portal Team 2018).

Other consequences of climate change are severe weather patterns. Warmer seawater has increased the frequency and strength of hurricanes (Stormfax Weather Almanac 2018). On average, storms have increased from 1851 to 2017:

\begin{tabular}{clc} 
Named Storms & \multicolumn{1}{c}{ Hurricanes } & Major Hurricanes \\
1851: 6 & $1851: 3$ & $1851: 1$ \\
2017: 17 & $2017: 10$ & $2017: 6$
\end{tabular}

The warmer climate increases evaporation from the land and water into the atmosphere, which increases flooding and major snowstorms (Union of Concerned Scientists 2011). Not only does this evaporation increase wet weather, but it also dries out the land and increases droughts and the chance for significant wildfires (Union of Concerned Scientists 2011). 
Climate change is destroying resources. Clean water necessary for living is being replaced by saltwater, lands that were once available for planting crops are now arid wastelands, and forests which are necessary for oxygen production are burning down. As climate change affects the world, humans are directly affected, and our ability to live and thrive on the planet is questionable in the future.

\section{Proposed Policy Alternatives}

There have been different global policies and initiatives created to address climate change. The most recent one was the 2015 Paris Agreement, which was signed by different countries agreeing to combat climate change to keep the temperature from increasing more than 2 degrees Celsius above pre-industrial levels (United Nations, n.d.). Not every state in the world signed the agreement, and some that did sign have since backed out. Some states feel that others would be given a free ride and not punished for noncompliance (Duke 2019). This is because "countries don't act collectively. They're sovereign" (Barrett 2017, 650).

One alternative would be to have the organizations that contribute to the emissions of greenhouse gasses agree to reduce these emissions. This would eliminate the need for all states to agree to a policy.

Another alternative would be to create a cooperative agreement among the countries instead of a collective agreement (Barrett 2017). A collective agreement like the Paris Agreement requires those states that sign it to abide by the agreement. A cooperative agreement would have incentives for states to sign it and repercussions for not signing.

\section{Analyzing Policy Alternatives and Making a Policy Recommendation}

Requiring organizations to decrease their rate of greenhouse emissions will require them to makes changes to their processes (Barrett 2017, 658). The benefit of this recommendation is that states will not have to make agreements with each other that are unenforceable. The individual corporations will bear the majority of the costs. The government could provide tax incentives for this reduction in emissions.

One downfall of this recommendation is the enforcement of it. The government will have to pay to regulate and check that the corporations are reducing their emissions. Another downfall of this recommendation is that it will cost these companies money upfront to create equipment and implement procedures. The costs could have a trickle-down effect from increasing prices to the consumers to being so cost prohibitive that the companies go out of business, and people lose their jobs, which affects the economy negatively.

A cooperative agreement among countries would be more beneficial than a collective agreement. The cooperative agreement would affect every state, either negatively or positively. The terms of the agreement would be that every state that signed the agreement agrees to reduce its greenhouse emissions. This agreement would be enforced through trade. 
States would trade with others that take steps and show that they are abiding by the terms of the agreement to reduce emissions. If a state did not sign the agreement, or if they did sign the agreement but did not adhere to the terms, then trade is cut off.

One downfall is that states ignore the agreement and trade with states that are making no efforts. At that point, there is no incentive to have an agreement. Another downfall would be that by not trading with noncompliant states, economies could be affected. States may not get goods that are necessary for their citizens. Alternatively, there could be price gouging and inflation on the costs of goods that are traded.

A benefit of the agreement is that by trading only with states that signed it and are compliant, the states that are not participating will see a benefit and will want to sign the agreement. The more states that participate, the more others will want to participate (Barrett 2017, 657). It becomes a win-win for everyone: everyone gets the benefit of trade, and because trade is based on the reducing of emissions, the world benefits because everyone is working to reduce it. There is no incentive for a state to get a free ride (Barrett 2017, 650).

\section{Implementing Policy Recommendation}

The cooperative agreement is the policy recommended for implementation. The next UN Climate Change Conference is scheduled for November 9-20, 2020 (SDG 2019). States should come up with terms for the cooperative agreement by November 1, 2020, to present at the conference. Individual states will need to work with their various branches of government to agree to what terms would be acceptable for a cooperative trade agreement to reduce greenhouse emissions.

After the terms have been presented, the states will agree after negotiating the terms for the cooperative agreement. The states should sign the final agreement by the date of COP 27. States will have 12 months to show that they are making changes to reduce emissions, and by 2022 the terms of the agreement will be enforced regarding trading.

Coming up with the terms of the agreements could have different impacts on the different governments. Some governments may lose funding from corporations that are required to make changes. If this funding is lost, then those in power could lose their place in the government. The citizens may be unhappy at increased costs, or changes in the way they live, and could show that unhappiness by removing people in power. The benefits would be that the citizens are happy and keep those in power. Additionally, the economy could benefit from new jobs, new opportunities for growth, and new trading opportunities.

\section{Conclusion}

Humans activity is causing climate change (The Ocean Portal Team 2018). If something is not done to slow it down and stop it, people will continue to lose their lives and livelihoods. In the past, people were aware that climate change was happening, but that it would not affect them, 
and those in the future could take care of it. That time is now, and if we do not do something, the future looks even grimmer.

The world needs to work together to save the earth and all her citizens. One way to affect climate change is to reduce greenhouse gas emissions. States would sign a cooperative agreement to reduce these emissions and agree to not trade with those who do nothing. The timeline to do so is appropriate as it will take time for states to form the agreement, and for them to enforce compliance of the reduction of emissions in their states.

\section{Bibliography}

Barrett, Scott. 2017. "Why Have Climate Negotiations Proved So Disappointing?” In Essential Readings in World Politics, edited by Karen A. Mingst and Jack L. Snyder, 649-59. New York: W. W. Norton \& Company, Inc.

Duke, Rick. 2019. "Leaving the Paris Agreement is a Bad Deal for the United States." Foreign Policy, May 19, 2019. Accessed December 14, 2019. https://foreignpolicy.com/2019/05/19/leaving-the-paris-agreement-is-a-bad-deal-for-theunited-states/.

Garner, Rob, and Brian Dunbar. 2017. "Rising Seas." Nasa, August 3, 2017. Accessed December 10, 2019. https://www.nasa.gov/goddard/risingseas.

GlobalChange.gov. n.d. "Sea Level Rise: Rate of Global Sea Level Rise is Increasing." Accessed November 23, 2019. https://www.globalchange.gov/browse/indicators/global-sea-level$\underline{\text { rise. }}$

SDG. 2019. "2020 UN Climate Conference UNFCCC COP 26." SDG Knowledge Hub. Accessed December 14, 2019. https://sdg.iisd.org/events/2020-un-climate-change-conferenceunfccc-cop-26/.

Stormfax Weather Almanac. 2018. "Atlantic Hurricane Numbers by Year: 1851-2017." Revised 2018. Accessed November 25, 2019. http://www.stormfax.com/huryear.htm.

The Ocean Portal Team. 2018. "Sea Level Rise." Smithsonian, April 2018. Accessed November 26, 2019. https://ocean.si.edu/through-time/ancient-seas/sea-level-rise.

Union of Concerned Scientists. 2011. "Climate Hot Map: Global Warming Effects Around the World." Accessed November 23, 2019. https://www.climatehotmap.org/global-warmingeffects/rain-and-snow.html.

United Nations. n.d. "Climate Change." Accessed September 21, 2019. https://www.un.org/en/sections/issues-depth/climate-change/. 
World Meteorological Organization. 2019. “Global Climate in 2015-2019: Climate Change Accelerates." September 22, 2019. Accessed November 20, 2019.

https://public.wmo.int/en/media/press-release/global-climate-2015-2019-climate-changeaccelerates. 